\title{
An Overview of Experiential Learning in Nursing Education
}

\author{
Rhoda Murray \\ Assistant Professor, Nurse Practitioner
}

Experiential learning is an important methodology within the theoretical belief of adult education. Experiential learning is an educational orientation aimed at integrating theoretical and practical elements of learning that emphasizes the importance of experience for learning. In nursing education, learning through experience is called "hands-on" learning, or learning by doing (Burnard, 1993). Experiential learning centers on active pedagogical strategies that engage students in the learning process. Strategies include simulations, role-playing, clinical experiences, case studies, problem or inquiry based learning, and concept mapping. Additionally, experiential learning can occur in the field or classroom. This paper will provide an overview of experiential learning based on the works of Dewey (1938) and Kolb (1984), explain how experiential learning differs from other types of learning used in nursing classrooms, and describe the challenges of experiential learning theory as it relates to learners in nursing programs.

\section{OVERVIEW OF EXPERIENTIAL LEARNING}

Based on the seminal works of Dewey (1938), experiential learning is the concept that learning occurs during and from experience. Silberman (2007) described experiential learning as the involvement of learners in concrete activities that enable them to experience what they are learning. Additionally, experiential learning involves the processing of knowledge and skills through experience, reflections, experimentation, and application. According to Akella (2010), experiential learning stresses a need for learner involvement in all educational activities. Furthermore, experiential learning addresses the concept of how experiences make learning meaningful.

Dewey originally wrote about experiential learning in 1938. Dewey (1938) asserted that learning occurs through experiences (Merriam, Cafferella, \& Baumgartner, 2007). According to Ord (2009), Dewy is the architect of experiential learning. Ord (2009) asserted that many theorists, including Kolb (1984), based their concepts on Dewey's early works. However, Dewey did not propose that all experiences produce learning, or growth, and that some experiences may mis-educate, meaning that all experiences are not meaningful experiences. As such, people do not always grow, or learn, from their experiences. For learning to occur, experiences must be genuine and learners must connect with the experience. Experiential learning is applicable throughout academia especially nursing. Through active, personal engagement, experiential learning provides learners the opportunity to learn from their own experiences and the experience of others.

Dewey (1938) identified several important notions on how experiential learning takes place. First, there must be a relationship between the education and the experience, meaning educational lessons must have an experiential component. Second, experiences must demonstrate continuity and interaction. Learning experiences cannot just happen but must be planned with meaning. The meaningful experience allows learners to build on their experiences and connect what they learned from their new experiences. The connection allows 
learners to see future consequences. Finally, the environment and the learner's interaction with the environment influence the experience. As such, the environment must be comfortable and conducive for learning to occur. Additional aspects of experiential learning are that each experience will be individualized based on the learner's past experiences and that learners will have different views of the same concept. The overall premise to Dewey's theory is that all experiences are personal and individualized to the learner. Finally, for learning to occur, the learner's past experiences must connect to the learner's future experiences and the experiences must be productive and genuine. As stated by Merriam, Cafferella, and Baumgartner (2007), creating a welcoming atmosphere, providing the right materials, and linking these materials to learners' past and future experiences are critical to assisting adults to learn from their experiences.

As previously stated, Kolb (1984) based his theory of experiential learning on the works of Dewey. He also drew from the works of Piaget and Lewin. Kolb defined experiential learning as the process whereby knowledge is created through the transformation of experience (Coffey, 2012). The four central stages of Kolb's theory are concrete experience, reflective observation, abstract conceptualization, and active experimentation. Kolb noted that all four stages must be present for students to learn from their experiences. In the concrete experience stage, learners must be open and willing to be involved in new experiences and the concrete experiences must be active experiences rather than passive experiences. As such, the learner must be directly involved with the material for learning to occur, and the concrete experience provides the basis for learning. During the concrete experience stage, there is an emphasis on relating the new experience to personal experiences, and feelings. The second stage, reflective observation, involves critically reflecting on the concrete experience. During reflective observation, the learner thinks back on the experience in order to ascertain what was learned from the concrete experience. As stated by Merriam, Caferrella, and Baumgartner (2007) observation and reflection allow the new experiences to be viewed from a variety of perspectives. In addition, reflection lets the learner evaluate the effectiveness of the experience. The third stage, abstract conceptualization entails constructing theories to explain the observations from the second stage. Additionally, learners use their analytical skills to combine the ideas and concepts realized in the first two stages. As stated by Kohonen (2007) learning in this stage occurs by rigorous thinking and by using a systematic approach to structure and frame the phenomena.

In the final stage, active experimentation, learners test the new ideas and concepts during practice. In this stage, learners apply the concepts learned in real life situations. This is the stage where clinical, simulation, or fieldwork occurs. Practical application results in tangible experiential material for reflection. The four stages presented by Kolb (1984) are cyclical in nature. As stated by Merriam, Cafferella, and Baumgartner (2007), Kolb pictured these stages as interrelated phases within a cyclical process, with progressive movement through each stage. Two examples of Kolb's theory in action follow: simulation and a case study in nursing.

\section{Simulation Example}

The concrete experience occurs when nursing students have psychomotor experiences of inserting foley catheters in the simulation lab. Reflective observation occurs when the students reflect on the experience, what they observed, and their feelings about the experience. Abstract conceptualization occurs they read and comprehend the indications for inserting foley catheters and the associated complications. Finally, active experimentation occurs when they can insert foley catheters during an actual clinical experience. Additionally, the students can relate the concepts and skills learned during simulation to real experiences. The nursing students can call on the prior experience to master the skill and apply this mastery to new and future foley catheter insertions. 


\section{Case Study Example}

A concrete experience occurs when, during a case study, students learn about congestive heart failure, its associated complications, and required nursing care. Reflective observation occurs when the students reflect on the case study to ascertain what was learned from the case study and their feelings about the case study. Abstract conceptualization occurs when the students comprehend the pathophysiology, clinical manifestations, and required nursing care when a patient has a congestive heart failure. Finally, active experimentation occurs when the students can care for a patient with congestive heart failure. The prior concrete experience, reflection, and comprehension allow the students to relate the concepts learned during the case study to what they are experiencing with the patient in the clinical setting. The learners can use the knowledge gained from the concrete experience to provide quality care to any future heart failure patients for whom they provide care.

Two central themes from both Dewey (1938) and Kolb (1984) are that for learning to occur the learner must reflect upon the experience and the experiential learning process is cyclical. Both theorists postulated that new and subsequent experiences must build on experiences for meaningful learning to occur. Additionally, the experience and the reflection must have quality and meaning. As stated by Fowler (2008), the nature of the reflection and quality of the experience must be significant for overall learning.

Other theorists offered theoretical perspectives on experiential learning, though Dewey (1938) and Kolb (1984) are the preeminent authorities. According to Merriam, Cafferella, and Baumgartner (2007), such theorists as Jarvis (1987), Boud, and Walker (1991), and Usher, Bryant, and Johnston (1997) offered conceptual views on experiential learning. Central to these theorists is the idea that experiential learning requires that learners to connect what they are learning in current experiences to past and future situations.

\section{DIFFERENCES FROM OTHER FORMS OF LEARNING}

Experiential learning is just one learning strategy used in nursing education. The goal of nursing education is to produce competent nurses who are self-directed and can think critically. Experiential learning activities assist learners in becoming self-directed, transformational learners. According to Ukpokodu (2002), experiential learning strategies are powerful tools in facilitating students' transformative learning. Self-directed, critically thinking nurses are necessary to meet the increasingly complex challenges facing healthcare today. As such, nurse educators need to use pedagogical approaches that assist learners in becoming self-directed, critical thinkers. As stated by O'Shea (2003), nurses unable to direct their own learning will not have the necessary skills to meet the changes in modern healthcare. As compared to the other learning strategies, experiential learning promotes self-direction and critical thinking.

Other strategies include traditional learning, computer-assisted learning, distance learning, and competency-based learning. Traditional learning approaches in nursing education include didactic lectures, memorization, return lab demonstrations, note taking, and multiple-choice exams. In contrast to experiential learning, traditional strategies are passive strategies and may not lead to self-direction or improved critical thinking skills. Whereas experiential learning is an active, learner-centered process, traditional approaches are more instructor centered. In addition, experiential learning provides learners with practical knowledge, activities, assignments, and experiences that they can apply to their work environment.

Experiential learning allows for more engagement by the learner in the learning process. This increased engagement results in a more intense, more meaningful learning experience than 
what may be achieved from traditional approachs. Unlike traditional classroom learning strategies, experiential classroom strategies involve the learner in performing activities and reflecting on these activities. Experiential classroom activities include case studies, simulations, role-play, problem-based learning, or other activities that use real life experiences as the basis for instruction. However, as postulated by Wingfield and Black (2008), any assignment can be experiential if it requires students to apply concepts learned in the classroom to what they will be expected to do in practice. Another contrast between experiential learning and traditional learning is that traditional learning might not be conducive to meeting a variety of learning needs or styles. According to DeYoung (2009), traditional approaches, such as lecturing, does not allow learners to interact with peers, manipulate data, or learn through other means, whereas experiential learning may meet a variety of learning needs or styles. As stated by Lisko and O’Dell (2010), traditional approaches may indicate technical mastery but do not facilitate the outcome of critical thinking, as experiential learning does.

Nursing education also employs computer-assisted learning. Computer-assisted learning involves using computers to help students master learning objectives. It allows learners to access, analyze, and manipulate information, and it also provides instant feedback that allows for real-time learning. Similar to experiential learning, computer-assisted learning is an active approach that makes learning interesting and memorable. As stated by DeYoung (2009), computer-assisted learning allows learners to interact in the learning situation, find information, respond to questions, and solve problems. In contrast to experiential learning, computer-assisted learning does not allow for personal and professional communication or interactions. Consequently, the personal interactions experienced through experiential learning are missing from computer-assisted learning. As a result, the learner does not experience socialization with the type of patients the learner may encounter in practice. Other differences include the level of skill and training required for computer-assisted learning as opposed to experiential learning.

Distance, or online, learning is a common form of learning in nursing education today. As noted by DeYoung (2009), courses delivered via the Internet are increasing, and greater than one million students are enrolled in some form of distance learning. Similar to computer assisted learning but different from experiential learning, distance learning lacks interaction. According to Womack, Lyons, Roskos, Byrne, and Staggers (1999), online learning is not an adequate substitute for the full, rich classroom experience. Other differences from experiential learning are the lack of immediate feedback and nonverbal communication, which can make learning experiences less meaningful.

Competency-based learning and education is a teaching and learning process that is individualized. It emphasizes what individuals must know and be able to do. Competencies are higher-level skills, including clinical judgment, critical reasoning, evidence-based practices, and relationship-centered care. Some aspects of these competences are being used in nursing classrooms, but only a few nursing schools have made the change to full competency based learning. Competency-based learning in nursing began in response to the nursing shortage. Competency-based learning is not widely used in nursing classrooms, but there are calls for its integration. In 2011, in their initiative on the future of nursing education, the Robert Woods Johnson Foundation called for moving nursing curriculum toward a competency-based learning model.

Overall, experiential learning is a better approach to helping students become self-directed. Experiential learning allows for active problem solving and practice-based learning. 
Fortunately, experiential learning activities can be incorporated into any of the learning methods discussed. Integrating experiential learning activities into traditional, computer assisted, or distance learning provides a richer, more meaningful experience for the learner.

\section{CHALLENGES OF EXPERIENTIAL LEARNING THEORY}

Experiential learning offers many benefits for nursing education and learners, but nursing students and educators may face challenges with experiential learning. One student challenge involves having sufficient time to experience the situation, reflect, and make meaning of the experience. Nursing students must cover a large quantity of content, and they may feel they do not have sufficient time to understand the experience. This lack of time leads to decreased time to reflect on the experience and internalize the experience to make it meaningful. For meaningful learning to occur, adequate time needs to be allotted for learners to participate in and reflect on the experience.

Another student challenge is resistance to participating in experiential learning activities. According to Billings and Halstead (2012), students socialized to a passive learning model may resist engaging in experiential learning activities. Consequently, students may not gain meaning from the experience. An additional learner challenge may be the lack of prior experiences to draw upon. Experiential learning calls for learners to relate past and present experiences, and novice or beginning nursing students may not have any prior knowledge or clinical experiences that relate to the new experience. As a result, the learners may have difficulty making meaning of the new experience.

Nursing programs and educators also face challenges in implementing experiential learning. For example, sufficient clinical placement sites may not be available for students to receive hands-on learning, nor may they have access to sufficient equipment or facilities for experiential activities. Already, clinical placement sites for training nursing students are in short supply. According to Grady (2011), the lack of clinical sites prevents students from receiving quality experiences. Nursing programs have begun using simulations as experiential learning activities. However, the expense of setting up and maintaining simulation labs may prevent nursing programs from using this technology. As noted by Billings and Halstead (2012), the expense of maintaining equipment, the need to fix the equipment, and the faculty workload are challenges in using simulation technology. Additional challenges include time and cost for faculty to develop adequate experiential activities, lack of faculty knowledge or experience in using experiential learning activities, and faculty reluctance to changing teaching approaches.

Developing effective, meaningful experiential learning activities takes time. As previously stated, nursing curricula cover a great deal of content. Nurse educators may choose to use passive learning approaches instead of experiential learning approaches in order to cover all of the required content. Faculty inexperience with experiential learning activities or lack of knowledge of the experiential learning theory may prevent faculty from using experiential learning strategies. Other important challenges are evaluating experiential learning activities and the potential that experiential learning might not prepare learners to pass certification examinations.

Despite the aforementioned challenges, experiential learning theory and activities are beneficial to nursing education. It provides nursing students with meaningful learning experiences, and they promote critical thinking, application, and analysis. Experiential learning provides nursing students with the essential skills needed to care for a complex patient population. 


\section{CONCLUSION}

The increasingly complexity in healthcare calls for nursing education programs to consider new learning strategies. Experiential learning provides a blueprint for preparing nurses to practice in the 21st century. Nurse educators are challenged to engage students and maximize learning in the classroom and clinical setting. Experiential learning allows educators to meet the goals of maximizing learning and making learning meaningful. Moreover, it is important for teachers to use strategies that promote critical thinking and self-directed, transformational learning. Experiential learning offers these capabilities and can be used to augment any other learning method. Nursing is a practice-based profession. Therefore, as an experience-based learning theory, experiential learning fits harmoniously with the philosophy and perspectives of nursing education.

\section{References}

Akella, D. (2010). Learning together: Kolb's Experiential Theory and its application. Journal Of Management and Organization, 16(1), 100+. Retrieved from http://www.questia.com/PM.qst?a=o\&d=5043041011

Billings, D., \& Halstead, J. (2012). Teaching in nursing: A guide for faculty (4th ed.). St. Louis, MO: Elsevier Saunders. Burnard, P. (1993). Using experiential learning methods with large groups of students: Network heading. Nurse Education Today, 13, 60-65.

DeYoung, S. (2009). Teaching strategies for nurse educators (2nd ed.). Upper Saddle, NJ: Pearson Education.

Grady, J. L. (2011). The virtual clinical practicum: An innovative telehealth model for clinical nursing education. Nursing Education Perspectives, 32(3), 189-194. doi:10.5480/1536-5026032.3.189

Kohonen V. (2007). Learning to learn through reflection-An experiential learning perspective. Retrieved from http://archive.ecml.at/mtp2/Elp_tt/Results/DM_layout/00_10/05/Supplementary\%20text\%20E.pdf

Lisko, S. A., \& O’Dell, V. (2010). Integration of theory and practice: experiential learning theory and nursing education. Nursing Education Perspectives, 31(2), 106-108. Retrieved from EBSCOhost

Merriam, S., Caffarella R., \& Baumgartner, L. (2007). Learning in adulthood: A comprehensive guide (3rd ed.). San Francisco: Jossey-Bass.

Ord, J. (2009). Experiential learning in youth work in the UK: A return to Dewey. International Journal of Lifelong Education, 28(4), 493-511. doi: 10.1080/02601370903031355

O'Shea, E. (2003). Self-directed learning in nurse education: A review of the literature. Journal of Advanced Nursing, 43(1), 62-70. Retrieved from EBSCOhost.

Silberman, M. (2007). The handbook of experiential learning. San Francisco, CA: Wiley.

Ukpokodu, N. (2002). Breaking through preservice teachers' defensive dispositions in a multicultural education course: A reflective practice. Multicultural Education, 9(3): 25-33.

Wingfield, S., \& Black, G. (2005). Active versus passive course designs: The impact on student outcomes. Journal of Education for Business, 81(2), 119-125. 